\section{MENINGITIS DUE TO CARCINOMATOSIS}

\section{CASE WITH FREE CARCINOMA CELLS IN CEREBROSPINAL FLUID}

BY

\author{
J. A. McMiLlAN, M.B., B.S., D.Path. \\ Louis Jenner Laboratory, St. Thomas's Hospital, \\ London
}

\section{[With Special Plate]}

The identification of carcinoma cells in the cerebrospinal fluid (C.S.F.) was first reported by Dufour (1904). The importance of this technique is well recognized, but nevertheless the demonstration of these cells in the C.S.F. in vivo remains the exception rather than the rule in cases of meningeal carcinomatosis. Technical difficulties in the preparation of a satisfactory film for cytological examination no doubt partly account for this.

Spriggs (1954) collected from the literature 66 cases in which malignant cells were found in the C.S.F. A high proportion of these cases were due to infiltration of the meninges by secondary carcinoma. Other reported cases are mentioned by McMenemey and Cumings (1959). It is known that carcinomatosis of the meninges may present no naked-eye abnormality at necropsy (Heathfield and Williams, 1956), and in these cases diagnosis is dependent on histology unless carcinoma cells have been found in the C.S.F. during life. The following case emphasizes these aspects of the disease.

\section{Case History}

A man aged 42 years was first admitted to hospital in October, 1960, when he was found to have a malignant ulcer in the pyloric region of the stomach. A Polya partial gastrectomy was performed. Histological examination of the ulcer showed a poorly differentiated, mucus-secreting adenocarcinoma.

He was readmitted in September, 1961, complaining of headaches, neck stiffness, and vomiting for three weeks. These symptoms had been increasing in severity, and at the time of admission he also had photophobia, occasional diplopia, and some difficulty in speech. On examination he was afebrile, photophobic, and showed marked neck stiffness with a positive Kernig's sign. There was slight dysarthria, but no localizing signs in the central nervous system; reflexes were brisk and the plantar responses normal. The fundi were also normal.

Investigations showed: Hb 14.7 g. per $100 \mathrm{ml}$; W.B.C. 5,700 per c.mm. (neutrophils $76 \%$, lymphocytes $19 \%$, monocytes $5 \%$ ) ; E.S.R. $12 \mathrm{~mm}$. in the first hour (Westergren). Lumbar puncture yielded a clear fluid, at a pressure of $120 \mathrm{~mm}$., containing 78 cells per c.mm. (lymphocytes $87 \%$, atypical cells $13 \%$ ). The protein content was $75 \mathrm{mg}$. per $100 \mathrm{ml}$. and the glucose level was too low to estimate. Culture proved sterile and no acid-fast bacilli were seen.

A subsequent lumbar puncture yielded a fluid at a pressure of $220 \mathrm{~mm}$. and with a glucose content of $7.5 \mathrm{mg}$. per $100 \mathrm{ml}$; and in a third sample the pressure was $200 \mathrm{~mm}$. and the glucose $7.0 \mathrm{mg}$. per $100 \mathrm{ml}$. In both these specimen the cytology was substantially the same as that of the first specimen.

An electroencephalogram showed an abnormal record without any focal features. The patient's condition steadily deteriorated and he died in a coma 13 days after admission.

\section{Cytology of Cerebrospinal Fluid}

The atypical cells were large (up to $26 \mu$ in diameter) and tended to occur in clumps of up to 20 cells, showing con- siderable variation in shape and size of the individual cells The nuclei were large $(12-20 \mu$ in diameter) in relation to the size of the cell and rather irregularly round in outline. Nucleoli were usually prominent. In some cells the cytoplasm was slightly foamy, and in others contained large vacuoles giving the cell a "signet-ring" appearance. No mitoses were seen (Special Plate, Fig. 1).

The other cells present were typical lymphocytes.

\section{Post-mortem Examination}

Deposits of secondary carcinoma were present in enlarged lymph-nodes in the mesentery, around the abdominal aorta, and along the upper border of the pancreas. There was no evidence of a recurrence of the carcinoma in the stomach remnant, and there were no other visceral metastases. The brain showed slight generalized congestion of the leptomeninges, and there was a small white opacity, $1 \mathrm{~cm}$. in diameter, of the arachnoid over the posterior surface of the left cerebellar hemisphere, though this area did not appear thickened. No evidence of tumour was visible to the naked eye. There was increased tentorial grooving of the under surface of the temporal lobes. Slices through the fixed brain failed to reveal any metastases, but there was some generalized oedema of the brain. The choroid plexus appeared normal ; so also did the spinal cord and meninges.

\section{Histology}

The tumour in the lymph-nodes was a poorly differentiated, mucus-secreting adenocarcinoma composed of sheets of irregular cells, some of which were of the "signet-ring" type. There were a few poorly formed acini. Sections from many areas of the brain all showed a fine infiltration of the pia-arachnoid by "signet-ring" carcinoma cells (Special Plate, Fig. 2). In some areas there was definite formation of acini. There was a tendency for the carcinoma cells to surround small blood-vessels, and in some areas a single layer of cells was found surrounding a small blood-vessel within the superficial brain tissue. No other metastases were found within the brain. The choroid plexus showed a similar diffuse infiltration by carcinoma cells, and sections taken at various levels showed similar changes in the leptomeninges of the spinal cord. Over the cerebral cortex the accumulation of carcinoma cells was greatest in the sulci, and carcinoma cells were infiltrating the pia between the convolutions of the grey matter.

\section{Discussion}

The main interest in this case is the finding of secondary carcinoma cells in the cerebrospinal fluid in a case presenting as one of subacute meningitis, though at necropsy there was no definite naked-eye evidence of intracranial metastases. Carcinoma cells were present in all three samples of C.S.F. submitted. These cells were first noticed in the counting-chamber, occurring as clumps of atypical cells among normal leucocytes. They were easily identified in stained films prepared from the centrifuged deposit of the C.S.F., and their morphology showed many features typical of carcinoma cells in C.S.F.

Recognition of malignant cells in C.S.F. is made easier by the relatively small variety of cell types present in C.S.F. The cells are obviously foreign to their environment and do not appear in other conditions causing a cerebrospinal pleocytosis. The cell morphology frequently resembles that of the primary tumour, and in addition usually shows some of the features of malignant cells in general, such as large cell size, with variation in size and shape of individual cells; high nuclear-cytoplasmic ratio; prominent nucleoli, and possibly mitoses (Spriggs, 1954). 
In this case air-dried films stained with Leishman's stain and wet films fixed in Schaudinn's fluid before being stained with Meyer's haemalum and eosin were both satisfactory, though the latter method gave greater cytological detail. In either case it was necessary that the centrifuged deposit be suspended in the minimum amount of fluid consistent with spreading a film.

In the cases hitherto described the commonest sites of primary growth have been stomach and bronchus. With regard to the dissemination of malignant cells in the C.S.F. Willis (1953) has suggested that this usually occurs from secondary deposits involving the ventricular walls, the choroid plexus, or the leptomeninges. The extensive involvement of the leptomeninges and choroid plexus in the present case together with the constant finding of carcinoma cells in the C.S.F. supports this, and it is clear that dissemination would be particularly easy from such a large surface area in contact with C.S.F.

Carcinomatosis of the meninges frequently produces a lymphocytic response in the C.S.F. In this case $87 \%$ of the cells present were lymphocytes. In cases such as this, which present clinically as subacute or chronic meningitis, this may lead to a misdiagnosis of tuberculous meningitis unless the carcinoma cells are also found. The absence of fever in these cases is significant, and should stimulate an adequate search for atypical cells.

Another finding frequently associated with carcinomatosis of the meninges is a low glucose level in the C.S.F. The mechanism of this change is uncertain, some observers believing that the fall is due to increased metabolism by the tumour cells, others that a mechanical block of the blood-brain barrier would prevent the passage of crystalloids, while still others believe that a combination of both these factors is usually present (McMenemey and Cumings, 1959). However, the general belief that the glucose level is lowest in those cases where there is extensive meningeal involvement is supported by this case, where the glucose level in all three samples of C.S.F. was extremely low, and indeed absent in one sample, and the meningeal involvement particularly diffuse.

The successful identification of malignant cells in the C.S.F. is primarily dependent on a satisfactory film for cytological examination, as it is most unlikely that the atypicality of any carcinoma cells present would always be apparent in the counting-chamber. It is suggested that films should be carefully examined in all cases of cerebrospinal pleocytosis of unknown aetiology, particularly where there is an associated cerebrospinal lymphocytosis, when the glucose level is unexpectedly low, or when a patient with subacute or chronic meningitis is afebrile.

It is also emphasized that the diagnosis of carcinomatous meningitis may be missed at necropsy unless a thorough histological examination is carried out.

\section{Summary}

A case of carcinomatosis of the meninges is reported Malignant cells were found in the cerebrospinal fluid in vivo, and this was associated with an extremely low glucose level in the fluid. Histological evidence of diffuse carcinomatous involvement of the leptomeninges was found at necropsy, though there was no naked-eye evidence of tumour.
The difficulties of diagnosis in this condition are discussed.

I wish to thank Dr. Evan Jones for permission to quote from the case history, Dr. R. Vaughan-Jones for the cytological preparations, and Professor R. C. Curran for the photomicrographs.

REFERENCES

Dufour, H. (1904). Rev. neurol., 12, 104.

Heathfield, K. W. G., and Williams, J. R. B. (1956). Brit. med. J., 1, 328 .

McMenemey, W. H., and Cumings, J. N. (1959). J. clin. Path., 12,400 .

Spriggs, A. I. (1954). Ibid., 7, 122.

Willis, R. A. (1953). Pathology of Tumours, 2nd ed. Butterworth, London.

\section{DIAGNOSTIC VALUE OF A SINGLE PLASMA PEPSINOGEN ESTIMATION} AN ASSESSMENT IN 500 CASES

BY

H. E. VICKERS, M.D.

Consultant Pathologist, Walton Hospital, Liverpool

AND

M. P. KENNEDY, B.Sc.

Senior Biochemist, Walton Hospital, Liverpool

The study of peptic ulceration has included a search for methods which will provide a reliable indication of total gastric activity. The clinician is particularly interested in those tests which will help him to decide whether or not there is an ulcer, and how he can cure it or relieve its symptoms. Edwards, Jepson, and Wood (1960) reviewed the relationship between gastric pepsin secretion and the uropepsinogen and plasma pepsinogen levels, and suggested that single estimations of the plasma pepsinogen would prove a helpful diagnostic test. There are many difficulties in transferring a research test satisfactorily to general diagnostic work. It has to be done by different people in different departments and under different conditions, of which pressure of other work is perhaps the most exacting. Only the most robust and reliable tests survive and prove suitable for indiscriminate use. We have used the method proposed by Edwards et al. in 500 cases under busy routine diagnostic conditions and have failed to substantiate their hopes for it.

\section{Method}

The method was based on that described originally by Mirsky et al. (Edwards et al., 1960).

Each batch of tests was done on the same batch of reconstituted plasma substrate, and only substrate which reconstituted completely was used. The substrate and patients' plasma mixture was initially standardized to a $p \mathrm{H}$ of 2 , estimated electrically. The tyrosine standard was prepared by dissolving $100 \mathrm{mg}$. of tyrosine and making up to $100 \mathrm{ml}$. with $\mathrm{N} / 10 \mathrm{HCl}$. A working standard was prepared freshly each day from this by diluting $5 \mathrm{ml}$. of the stock standard to $100 \mathrm{ml}$. with water.

The final steps, in which all tubes were treated identically, were as follows. $2 \mathrm{ml}$. of filtrate and $3 \mathrm{ml}$. of dilute Folin and Ciocalteau reagent (B.D.H. reagent diluted one part reagent to two parts of water) were 


\section{W. J. IRVINE: CYTOTOXIC FACTOR IN THYROID DISEASE}

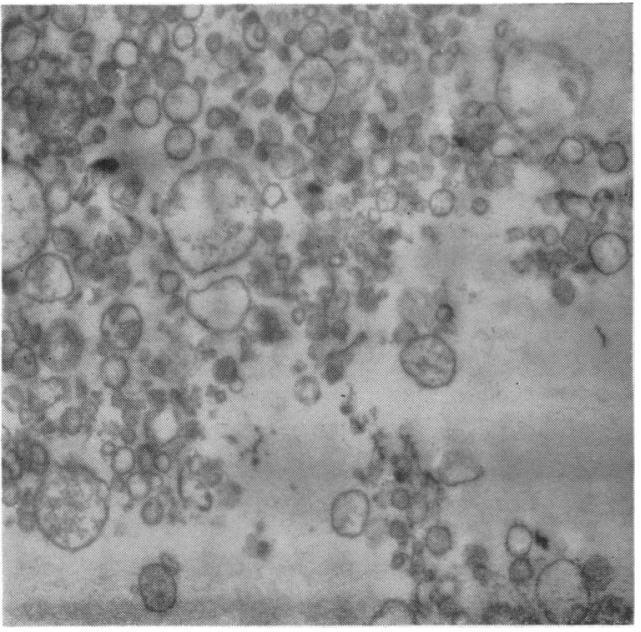

Fig. 1

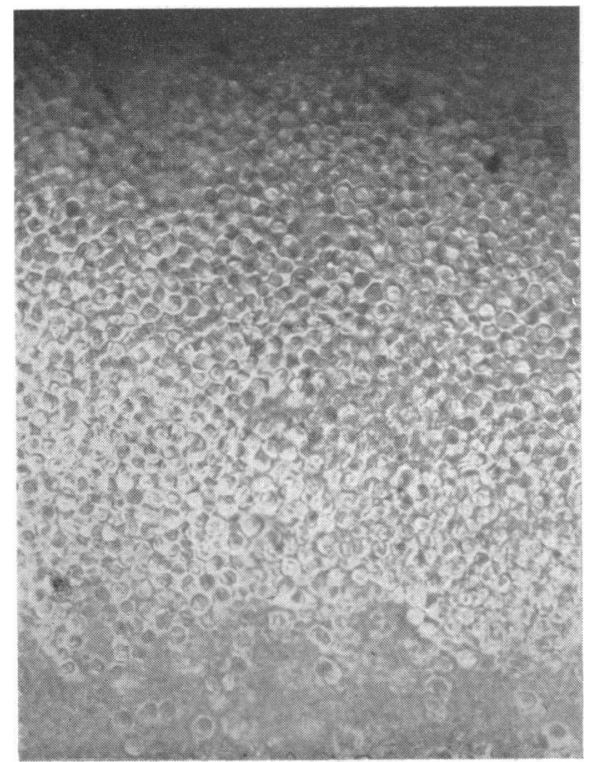

Fig. 4

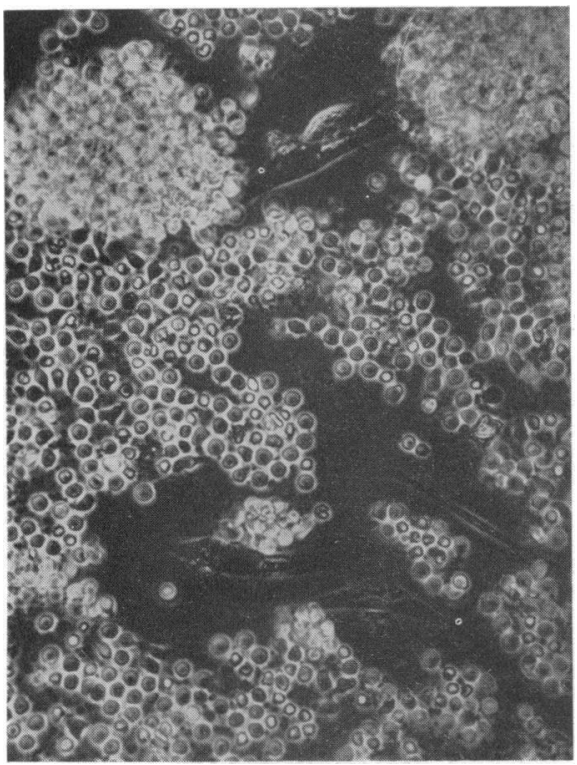

Fig. 5

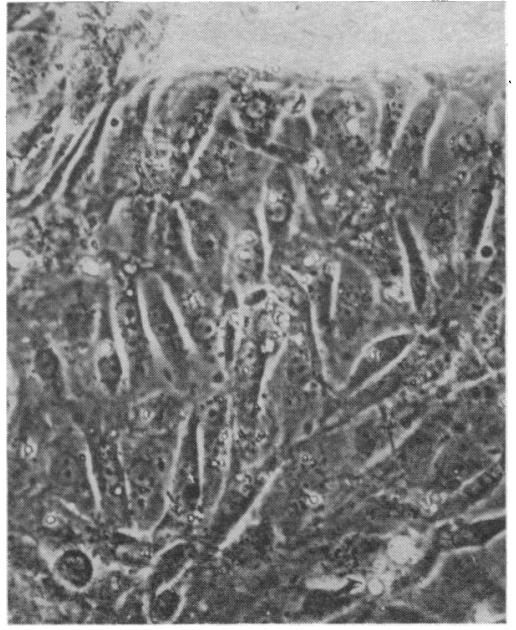

FIG. 2

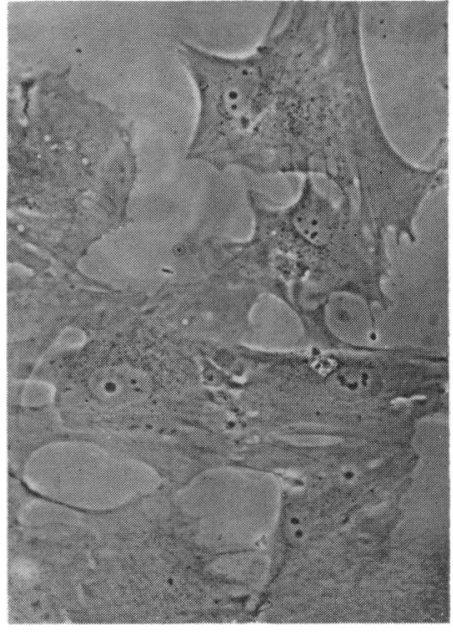

FIG. 3

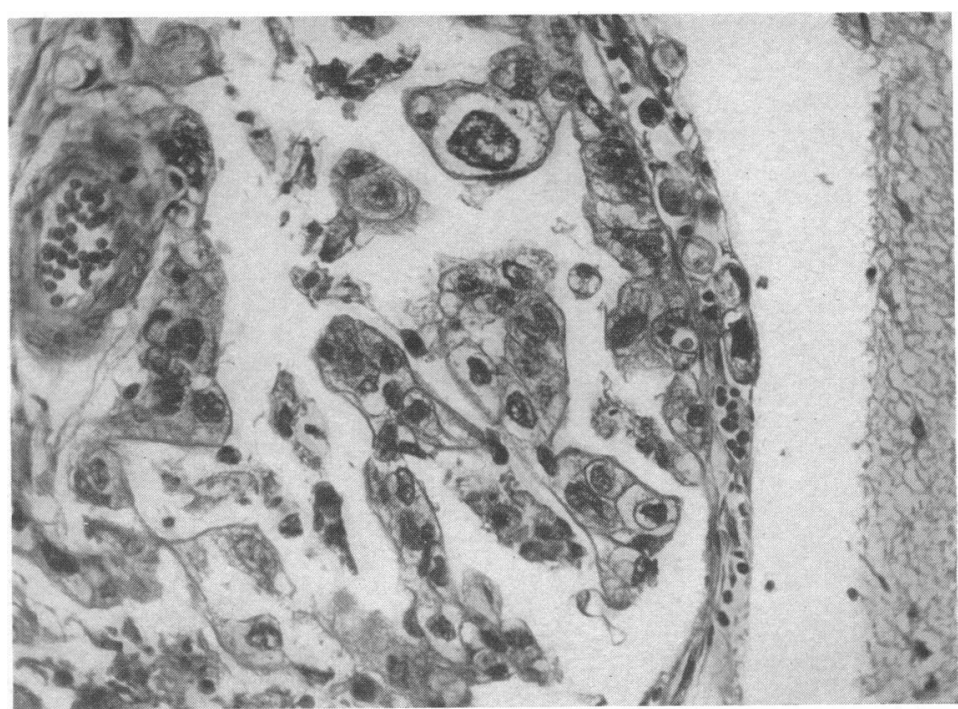

FIG. 2.-Carcinoma cells infiltrating pia-arachnoid. (H. and E. $\times 240$.) 